The World of Numbers

By Herbert McKay. Pp. vii + 198. (Cambridge : At the University Press, 1946.) 8s. 6d. net.

T HERE has been no shortage of books purporting to make elementary mathematics 'popular' during the years since the beginning of the War; but good books of this class have been exceedingly rare. McKay's is a good book. It covers familiar ground, but its freshness, boldness and thoroughness are obviously the product of considerable thought and extensive reading on the part of the author. Numerologists, circle squarers, gematria addicts and perhaps Shakespeare are easy mathematical prey for an author, but McKay goes further by giving Bernard Shaw a severe and well-deserved admonition and by showing how "Whitaker's Almanack" and "Kaye and Laby" come to grief.

The numerous arithmetical calculations appear to be reliable, but a number of minor slips occur in other directions. "One horse-power would boil a pint of ice-cold water in $5 \frac{1}{4}$ minutes" means well but is badly expressed; defining a calorie as the heat required to raise a cubic centimetre of water $1^{\circ} \mathrm{C}$. (p. 118) is a new idea, and the frequent conversion of decimal answers to a calculation into fractions with awkward denominators is a dubious step seeing that the arithmetic could not be followed without reasonable familiarity with decimals. The introduction of poundal (undefined) on page 98 spoils the continuity of an argument proceeding smoothly in gravitational units, and the fact that "Cavendish found the value of $G 6 \cdot 7$ ", without reference to units, is rather disturbing. The author appears to mean $6.7 \times 10^{-8}$ dyne-cm. ${ }^{2}$ per gm. ${ }^{2}$, but this does not fit well into an explanation which is wholly in British practical units. The book would be improved if poundals were deleted altogether. Two chaptersthose dealing with symbols and imaginary quantities -are out of balance with the remainder of the book. It is little hard on the reader when an author introduces differentiation on one page (as a limiting process without having mentioned either calculus or limits before), differentiates the sine function on the next page, introduces Taylor's and Maclaurin's series on the third and covers the exponential theorem, logarithmic series and series for $\sin \theta$ and cosine in the two and a half pages that complete the chapter ! The right-angle symbol for factorial is, presumably, still regarded as a matter of opinion. Its bursts into renewed life in Great Britain are less and less frequentit will soon be dead. These are minor criticisms of a readable and well-written book.

\section{Birds in Colour}

By Walter E. Higham. Pp. $176+48$ plates. (London: Wm. Collins, Sons and Co., Ltd., 1946.) $25 s$.

$\mathrm{M}$ R. HIGHAM'S book is an addition to ornitholog. ical literature of which he and his publishers might rightly be proud. As the title indicates, the main purpose of the book is to present some of the remarkable coloured photographs which the author has so assiduously and skilfully collected. Altogether there are eighty-nine photographs, and many of them are cuttings from the three coloured films, "British Featherland", "Featherland of the Farne Islands and the Bass Rock" and "Hungarian Featherland", which were the products of Higham's resourceful camera. The photographe, from his Hungarian film, of birds which, like the purple and great white herons, are uncommon visitors to Britain, bring added charm and value for readers whose connexions with mid-European avifauna have been so long interrupted. The text is incidental to the photographs, and, although it contains little new for the specialist, would be of particular interest to the beginner as an introduction to the science and art of bird-photography.

In recommending this work to all bird-lovers, it must be said that the photographs themselves are mixed in quality, and that much remains to be done technically before the bird photographer can fairly claim that his coloured pictures are accurate reproductions of all the shades and tones of his models. Too many of Higham's birds, for example, have eyes which are but blacked-in circles containing white spots excentrically placed. The author can feel gratified, however, by the awareness that his efforts in colour photography will have done much to extend an ever-growing circle of bird-watchers and to improve the science of colour photography. T. H. H.

\section{Colloids}

Their Properties and Applications. By A. G. Ward. Pp. vi $+134+6$ plates. (London, Glasgow and Bombay : Blackie \& Son, Ltd., 1945.) 5s. net.

THE scientific study of colloids has made great strides between the two World Wars. This is clearly brought out by comparing Mr. Ward's book with Hatschek's "Introduction to the Physics and Chemistry of Colloids" which was published in 1919 (third edition). The new knowledge of colloids has arisen mainly from studies of the behaviour of monomolecular and polymolecular films at surfaces and interfaces, and from studies of natural and synthetic polymers, studies which have enabled the classical physical laws to be extended to the special case of colloids. Mr. Ward's book deals clearly and concisely with these advances in our knowledge. It is divided into three parts : the nature of the colloidal state, colloidal systems, and colloids in industry and in living matter respectively, thus enabling the reader to find what particularly interests him without much effort. There is a short but carefully selected list of books for further study.

The author's modest claim to have written an elementary account of colloid science is fully substantiated. It is in fact a stimulating little book which can be read with profit, both by those with little previous knowledge of the subject and by those who wish to renew an old acquaintance with a fascinating and rapidly expanding field. E. H. CALLOW

\section{An Introduction to Industrial Mycology}

By George Smith. Third edition. Pp. xv + 271. (London: Edward Arnold and Co., Ltd., 1946.) 20s. nөt.

7 HE earlier editions of this very useful book were remarkable for the clarity and quality of the photomicrographs. They are still better in the third edition, and seven more have been added, while four "which were not considered satisfactory" have been replaced. This results in an even more useful volume. It serves alike as a readable introduction to mycological technique and literature, and a work of reference for the specific uses of mould fungi in industry. Time has but strengthened the high praise of an earlier review (Nature, 152, 173; 1943). The text has only been changed in detail, as war-time restrictions were still in force when it was revised. It must be left to subsequent editions to describe many of the interesting problems involving the activities of moulds which have arisen in various industries during the war years.

J. G. 